\title{
Fuzzy Approach to Replacement Problem with Value of Money Changes with Time
}

\author{
Pranab Biswas \\ Assistant Teacher \\ Sardanga High School \\ P.O. - Chakdaha, Nadia, \\ West Bengal, 741222, India
}

\author{
Surapati Pramanik \\ Assistant Professor \\ Nandalal Ghosh B.T. College, Panpur, \\ P.O. - Narayanpur, North 24 Parganas \\ West Bengal, 743126, India
}

\begin{abstract}
Fuzzy set has been applied in many real applications to handle uncertainty. The aim of the paper is to study the replacement problem with uncertainty. This problem involves capital cost, scrap value or salvage value, maintenance cost or operating cost, and rate of interest having an imprecise value. Here, we assume the imprecise values as positive trapezoidal fuzzy numbers. Moreover, we consider that the value of money changes with fuzzy rate of interest due to market fluctuations. To deal with this type of problem, we first find out the present worth value of money and then determine the fuzzy annualized costs. By using Yager's ranking method, comparison of fuzzy annualized costs is done to obtain an optimal replacement policy. Numerical example is provided to check the validity of the proposed method.
\end{abstract}

\section{General Terms}

Replacement problem.

\section{Keywords}

Fuzzy sets, Fuzzy replacement problem, Replacement time, Trapezoidal fuzzy number.

\section{INTRODUCTION}

Replacement problem (RP) is one of the practical areas in engineering economics. The problem of replacement arises in our daily life when any one of the components of productive resources, such as machinery, building deteriorates due to time or usage. When any production facility is new, it works with full operating efficiency. With passage of time and due to usage, it may become old, some of its components wear out, and the operating efficiency of the facility may gradually decreases. To regain the efficiency, maintenance is to be needed. When first maintenance is attended, its performance is slightly reduced. In the second maintenance, it is more reduced than previous one. Like this the facility deteriorates, and finally the operating efficiency reduces to some desired level of performance, where it is not economical to use the facility for further production, as the maintenance cost will be very high, and the unit production cost also increases. Therefore, the replacement of the facility is due at this stage. A large number of discussions on RP exist in the literature. Bellman [1] first developed the replacement problem as a dynamic programming to find out the optimal age to replace the equipment. Alchian [2] considered replacement problem, when operating cost of equipment involves linear function of time. Drefus [3] discussed RP with exponentially bounded operating costs. Ohnishi [4] studied optimal repair and replacement problem under average cost criterion as a semi Markov decision.

Dimitrakos and Kidis [5] considered a system that deteriorates with age and may experience a failure at any time. They developed an algorithm based on the embedding technique and then generate a sequence of improving control limit policy. Mahdavi and Mahdavi [6] discussed an optimization of age replacement policy using reliability based heuristic model. Zhao et al. [7] formulated three kinds of replacement models combined with additive and independent damages. Nazed et al [8] discussed one stage two-machine replacement strategy based on the Bayesian inference method.

In our real world system, there are elements of uncertainty in the process or its parameters, which may lack precise definition or precise measurement especially when the system involves human judgment. When developing a model of a system of uncertainty, the decision maker can either ignore the uncertainty or try to deal with uncertainty. Ignoring the uncertainty, decision maker obtains the results in a deterministic model of the process with precise values of all parameters. To deal with uncertainty, a decision maker uses specific paradigms such as interval analysis, probability theory, fuzzy set theory, possibility theory, or evidence theory.

The choice of paradigm depends on the nature of the uncertainty. When the probabilities are specified for outcomes, then the theory of Von Neumann and Morhenstern [9] provides the tools necessary to determine the optimal decision. To deal with uncertainty, which is different from probability theory, Zadeh [10] developed the concept of fuzzy set theory in 1965. This theory has been developed and applied to numerous areas such as control, decision-making, engineering, medicine, investment and finance. In recent years, the uses of nonprobabilistic uncertainty and especially fuzzy sets have caught much attention in the area of economic analysis [11-13]. Ward [14] studied discounted fuzzy cash flow problem. Uncertainty occurs in replacement and maintenance decisions in various ways. Chiu and Park [15] use fuzzy numbers in cash flow analysis and provide a good survey of the major methods for ranking mutually exclusive fuzzy projects. Recently, Biswas and Pramanik [16] developed a method of finding the optimal 
replacement time of equipment of fuzzy replacement problem with trapezoidal fuzzy numbers and triangular fuzzy numbers using Yager's ranking method.

In this paper, we consider a realistic replacing problem where capital cost $(\tilde{\mathrm{C}})$, scrap value $(\tilde{\mathrm{S}})$, maintenance cost or running cost $\left(\tilde{R}_{n}\right)$ of equipment are imprecise in nature. These imprecise quantities will be represented by positive triangular fuzzy number (TFNs) or trapezoidal fuzzy numbers (TrFNs). We assume that the replacement of equipment deteriorates with time and the fuzzy maintenance cost goes on increasing with usage or age or time. Then, we have to find out optimum time of replacing the item. Here, we consider the value of money decreases with fuzzy rate of interest $(\tilde{\mathbf{r}})$, that is known as its discounted factor or depreciation ratio. Discounted factor is represented by $(\tilde{\mathrm{v}})$. With this discounted factor, we determine the weighted average fuzzy cost. Our objective is to find the minimum fuzzy average cost. Comparison of fuzzy average costs is done by a Yager's ranking method [17].

The remaining paper is organized as follows. In section 2, preliminaries of fuzzy sets are presented. In section 3, formulation of replacement model is given. In section 4 , the proposed model on fuzzy replacement problem when the value of money changes with time. An example has been given to demonstrate the effectiveness of the proposed method in section 5. Finally, section 6 presents the conclusions.

\section{PRELIMINARIES OF FUZZY SET 2.1 Definition}

Fuzzy set: A fuzzy set $\tilde{\mathrm{A}}$ in a universe of discourse $X$ is defined by $\tilde{\mathrm{A}}=\left\{\left\langle\mathrm{x}, \mu_{\tilde{\mathrm{A}}}(\mathrm{x})\right\rangle \mid \mathrm{x} \in X\right\}$, where $\mu_{\tilde{\mathrm{A}}}(\mathrm{x}): X \rightarrow[0,1]$ is called the membership function of $\tilde{\mathrm{A}}$ and $\mu_{\tilde{\mathrm{A}}}(\mathrm{x})$ is the degree of membership to which $\mathrm{x} \in \tilde{\mathrm{A}}$.

\subsection{Definition}

A fuzzy set $\tilde{\mathrm{A}}$ on $R$ is convex if and only if for any $\mathrm{x}_{1}, \mathrm{x}_{2} \in X$, the membership function of $\tilde{\mathrm{A}}$ satisfies the inequality $\mu_{\tilde{\mathrm{A}}}\left(\lambda \mathrm{x}_{1}+(1-\lambda) \mathrm{x}_{2}\right) \geq \min \left\{\mu_{\tilde{\mathrm{A}}}\left(\mathrm{x}_{1}\right), \mu_{\tilde{\mathrm{A}}}\left(\mathrm{x}_{2}\right)\right\}$;

$0 \leq \lambda \leq 1$.

\subsection{Definition}

A fuzzy set $\tilde{\mathrm{A}}$ of the universe of discourse $X$ is called a normal fuzzy set if there exists at least one $\mathrm{x} \in X$ such that $\mu_{\tilde{\mathrm{A}}}(\mathrm{x})=1$.

\subsection{Definition}

A fuzzy set $\tilde{\mathrm{A}}$, defined on the universal set of real number $R$, is said to be a fuzzy number, if its membership function has the following characteristics. i) $\tilde{\mathrm{A}}$ is convex, ii) $\tilde{\mathrm{A}}$ is normal and iii) $\mu_{\tilde{\mathrm{A}}}(\mathrm{x})$ is piecewise continuous.

\subsection{Definition}

A trapezoidal fuzzy number $\tilde{a}$ is denoted by $\left(a_{1}, a_{2}, a_{3}, a_{4}\right)$ where $a_{1}, a_{2}, a_{3}, a_{4}$ are real numbers and its membership function $\mu_{\tilde{\mathrm{a}}}(\mathrm{x})$ is given by

$$
\mu_{\tilde{a}}(x)= \begin{cases}0, & x \leq a_{1}, \\ \frac{x-a_{1}}{a_{2}-a_{1}}, & a_{2} \leq x \leq a_{1}, \\ 1, & a_{2} \leq x \leq a_{3}, \\ \frac{a_{4}-x}{a_{4}-a_{3}}, & a_{3} \leq x \leq a_{4}, \\ 0, & x \geq a_{4}\end{cases}
$$

$\mu_{\tilde{\mathrm{a}}}(\mathrm{x})$ satisfies the following conditions.

1. $\mu_{\tilde{\mathrm{a}}}(\mathrm{x})$ is a continuous mapping from $R$ to closed interval $[0,1]$

2. $\mu_{\tilde{\mathrm{a}}}(\mathrm{x})=0$ for every $\mathrm{x} \in\left(-\infty, \mathrm{a}_{1}\right]$

3. $\mu_{\tilde{a}}(x)$ is strictly increasing and continuous on $\left[a_{1}, a_{2}\right]$

4. $\mu_{\tilde{a}}(x)=1$ for every $x \in\left[a_{2}, a_{3}\right]$

5. $\mu_{\tilde{a}}(x)$ is strictly decreasing and continuous on $\left[a_{3}, a_{4}\right]$

6. $\mu_{\tilde{a}}(x)=0$ for every $x \in\left[a_{4}, \infty\right)$

\subsubsection{Definition}

A trapezoidal fuzzy number $\widetilde{\mathrm{A}}=\left(\mathrm{a}_{1}, \mathrm{a}_{2}, \mathrm{a}_{3}, \mathrm{a}_{4}\right)$ is called nonnegative (non-positive), denoted by $\tilde{\mathrm{A}} \geq 0(\tilde{\mathrm{A}} \leq 0)$, if and only if $a_{1} \geq 0\left(a_{1} \leq 0\right)$. A trapezoidal fuzzy number said to be positive (negative) TrFN i.e. $\tilde{\mathrm{A}}>0(\tilde{\mathrm{A}}<0)$ if and only if $\mathrm{a}_{1}>0$ $\left(\mathrm{a}_{1}<0\right)$.

\subsubsection{Definition}

Two trapezoidal fuzzy numbers $\tilde{\mathrm{A}}=\left(\mathrm{a}_{1}, \mathrm{a}_{2}, \mathrm{a}_{3}, \mathrm{a}_{4}\right)$ and $\widetilde{\mathrm{B}}=\left(\mathrm{b}_{1}\right.$, $\left.b_{2}, b_{3}, b_{4}\right)$ are said to be equal i.e. $\tilde{A}=\tilde{B}$ if and only if $a_{i}=b_{i}$, $\mathrm{i}=1,2,3,4$.

\subsubsection{Definition}

The $\alpha$-cutset of a fuzzy set $\tilde{\mathrm{A}}$ is a crisp set defined by $\tilde{\mathrm{A}}_{\alpha}=\left\{\mathrm{x} \in \mathrm{X} / \mu_{\tilde{\mathrm{A}}}(\mathrm{x}) \geq \alpha\right\}$.

\subsection{The Algebraic Operation on Trapezoidal Fuzzy Numbers}

Zadeh's extension principle is used to calculate membership function after mapping fuzzy sets through a function. The extension principle is defined as follows: Let fuzzy sets $\tilde{\mathrm{A}}_{1}$, $\tilde{\mathrm{A}}_{2}, \ldots, \tilde{\mathrm{A}}_{\mathrm{n}}$ be defined on universe $X_{1}, X_{2}, \ldots, X_{\mathrm{n}}$. the mapping for these particular input sets $\mathrm{P}=\mathrm{f}\left(\tilde{\mathrm{A}}_{1}, \tilde{\mathrm{A}}_{2}, \ldots, \tilde{\mathrm{A}}_{\mathrm{n}}\right)$, where the membership function of the image $\mathrm{P}$ is defined as $\mathrm{f}_{\mathrm{P}}=\sup _{\mathrm{y}=\mathrm{f}\left(\mathrm{x}_{1}, \mathrm{x}_{2}, \ldots, \mathrm{x}_{\mathrm{n}}\right)}\left\{\left[\min \mathrm{f}_{\widetilde{\mathrm{A}}_{1}}\left(\mathrm{x}_{1}\right), \mathrm{f}_{\widetilde{\mathrm{A}}_{2}}\left(\mathrm{x}_{2}\right), \ldots, \mathrm{f}_{\widetilde{\mathrm{A}}_{\mathrm{n}}}\left(\mathrm{x}_{\mathrm{n}}\right)\right]\right\}$.

For a trapezoidal fuzzy number, the extended algebraic operations based on this extension principle are laborious. This leads to the use of approximation formula discussed by Dubois and Prade (1980) [18-20], Kauffmann and Gupta (1991) [21]. This approximation can be improved by repeated use of $\alpha$-cuts. However, these will increase the complexity of computations in parameter estimation. It is useful in modeling and cash flow analysis.

\subsection{Definition}

Let $\tilde{\mathrm{A}}=\left(\mathrm{a}_{1}, \mathrm{a}_{2}, \mathrm{a}_{3}, \mathrm{a}_{4}\right)$ and $\tilde{\mathrm{B}}=\left(\mathrm{b}_{1}, \mathrm{~b}_{2}, \mathrm{~b}_{3}, \mathrm{~b}_{4}\right)$ be two trapezoidal fuzzy numbers where $a_{1} \leq a_{2} \leq a_{3} \leq a_{4}$ and $b_{1} \leq b_{2} \leq b_{3} \leq b_{4}$ 
then, the following extended algebraic operation can be defined as Bansal [22].

\subsubsection{Definition}

Image of $\tilde{\mathrm{A}}:-\tilde{\mathrm{A}}=\left(-\mathrm{a}_{4},-\mathrm{a}_{3},-\mathrm{a}_{2},-\mathrm{a}_{1}\right)$

\subsubsection{Definition}

Inverse of $\widetilde{\mathrm{A}}: \widetilde{\mathrm{A}}^{-1} \cong\left(1 / \mathrm{a}_{4}, 1 / \mathrm{a}_{3}, 1 / \mathrm{a}_{2}, 1 / \mathrm{a}_{1}\right)$ when $\mathrm{a}_{1}>0$.

\subsubsection{Definition}

Addition: $\tilde{\mathrm{A}}+\widetilde{\mathrm{B}}=\left(\mathrm{a}_{1}, \mathrm{a}_{2}, \mathrm{a}_{3}, \mathrm{a}_{4}\right)+\left(\mathrm{b}, \mathrm{b}_{2}, \mathrm{~b}_{3}, \mathrm{~b}_{4}\right)$

$=\left(a_{1}+b_{1}, a_{2}+b_{2}, a_{3}+b_{3}, a_{4}+b_{4}\right)$

\subsubsection{Subtraction}

Subtraction: $\tilde{\mathrm{A}}-\tilde{\mathrm{B}}=\left(\mathrm{a}_{1}, \mathrm{a}_{2}, \mathrm{a}_{3}, \mathrm{a}_{4}\right)-\left(\mathrm{b}, \mathrm{b}_{2}, \mathrm{~b}_{3}, \mathrm{~b}_{4}\right)$

$=\left(a_{1}-b_{4}, a_{2}-b_{3}, a_{3}-b_{2}, a_{4}-b_{1}\right)$

\subsubsection{Multiplication}

If $\mathrm{k}$ is a scalar constant and $\otimes$ denotes the extended multiplication,

$\mathrm{k} \otimes \tilde{\mathrm{A}}=\left\{\left(\mathrm{ka}_{1}, \mathrm{ka}_{2}, \mathrm{ka}_{3} \mathrm{ka}_{4}\right), \quad \mathrm{k}>0\right.$

$\mathrm{k} \otimes \tilde{\mathrm{A}}=\left\{\left(\mathrm{ka}_{4}, \mathrm{ka}_{3}, \mathrm{ka}_{2}, \mathrm{ka}_{1}\right), \mathrm{k}<0\right.$

$\tilde{\mathrm{A}} \otimes \tilde{\mathrm{B}} \cong\left\{\left(a_{1} b_{1}, a_{2} b_{2}, a_{3} b_{3}, a_{4} b_{4}\right) \quad\right.$ if $a_{1} \geq 0, b_{1} \geq 0$.

\subsubsection{Division}

Finally if $\mathrm{a}_{1} \geq 0, \mathrm{~b}_{1}>0$ and $\varnothing$ denotes the extended division,

$\tilde{\mathrm{A}} \varnothing \tilde{\mathrm{B}}=\left(\frac{\mathrm{a}_{1}}{\mathrm{~b}_{4}}, \frac{\mathrm{a}_{2}}{\mathrm{~b}_{3}}, \frac{\mathrm{a}_{3}}{\mathrm{~b}_{2}}, \frac{\mathrm{a}_{4}}{\mathrm{~b}_{1}}\right)$.

\subsection{A General Formula for n-th Power of Trapezoidal Fuzzy Number}

Lemma: let $\tilde{\mathrm{A}}=\left(\mathrm{a}_{1}, \mathrm{a}_{2}, \mathrm{a}_{3}, \mathrm{a}_{4}\right)$ be a trapezoidal fuzzy number, then $(\tilde{\mathrm{A}})^{\mathrm{n}}=\left(\mathrm{a}_{1}, \mathrm{a}_{2}, \mathrm{a}_{3}, \mathrm{a}_{4}\right)^{\mathrm{n}}=\left(\mathrm{a}_{1}^{\mathrm{n}}, \mathrm{a}_{3}^{\mathrm{n}}, \mathrm{a}_{3}^{\mathrm{n}}, \mathrm{a}_{4}^{\mathrm{n}}\right)$, where

$0 \leq \mathrm{a}_{1} \leq \mathrm{a}_{2} \leq \mathrm{a}_{3} \leq \mathrm{a}_{4}$ are each of real number, $\mathrm{n}$ is a natural number,

Proof: To prove this, we use the principle of mathematical induction. For $\mathrm{n}=1$, the statement is true because $\left(\mathrm{a}_{1}, \mathrm{a}_{2}, \mathrm{a}_{3}, \mathrm{a}_{4}\right)^{1}$ $=\left(a_{1}, a_{2}, a_{3}, a_{4}\right)$. Similarly, it can be shown that it is true for $\mathrm{n}=2$.

Let us assume that the statement is true for some natural number $\mathrm{n}=\mathrm{m}$.

Then, $\left(a_{1}, a_{2}, a_{3}, a_{4}\right)^{m} \cong\left(a_{1}^{m}, a_{2}^{m}, a_{3}^{m}, a_{4}^{m}\right)$.

Now we examine for the case of $n=m+1$.

$$
\begin{aligned}
& \left(a_{1}, a_{2}, a_{3}, a_{4}\right)^{m+1} \cong\left(a_{1}, a_{2}, a_{3}, a_{4}\right) \otimes\left(a_{1}, a_{2}, a_{3}, a_{4}\right)^{m} \\
& \cong\left(a_{1}, a_{2}, a_{3}, a_{4}\right) \otimes\left(a_{1}^{m}, a_{2}^{m}, a_{3}^{m}, a_{4}^{m}\right) \\
& \cong\left(a_{1} a_{1}^{m}, a_{2} a_{2}^{m}, a_{3} a_{3}^{m}, a_{4} a_{4}^{m}\right) \\
& \cong\left(a_{1}^{m+1}, a_{2}^{m+1}, a_{3}^{m+1}, a_{4}^{m+1}\right)
\end{aligned}
$$

This shows that the statement is true for $n=m+1$, if it is true for $\mathrm{n}=\mathrm{m}$.

By the principle of mathematical induction, the statement is true for all natural numbers $\mathrm{n}$. This completes the proof

\subsection{Definition}

For a convex fuzzy number $\tilde{\mathrm{C}}$, the Yager's Ranking index Y

$(\tilde{\mathrm{C}})$ is defined by $\mathrm{Y}(\tilde{\mathrm{C}})=\int_{0}^{1} 0.5\left(\mathrm{C}_{\alpha}^{\mathrm{L}}+\mathrm{C}_{\alpha}^{\mathrm{U}}\right) \mathrm{d} \alpha$
Here $\left(\mathrm{C}_{\alpha}^{\mathrm{L}}, \mathrm{C}_{\alpha}^{\mathrm{U}}\right)$ is a $\alpha$-level cut of fuzzy number $\tilde{\mathrm{C}}$.

\section{FORMULATION OF REPLACEMENT MODEL}

We consider replacement policy when the equipment deteriorates with time and the value of money changes with time. Our purpose is to evaluate the optimum replacement time of an item with these criterion.

Let the initial cost of the equipment be $C$ and let $R_{n}$ be operating cost in year $n$. Let $r$ be the rate of interest in such a way that $v=$ $(1+r)^{-1}$ is the discount rate. We find the weighted average cost of all the previous $n$ years' costs with weights $1, \mathrm{v}, \mathrm{v}^{2}, \mathrm{v}^{3}, \mathrm{v}^{\mathrm{n}-1}$ respectively. The expression for weighted average cost is given by

$$
\mathrm{W}(\mathrm{n})=\frac{\mathrm{C}+\mathrm{R}_{1}+\mathrm{v} \mathrm{R}_{2}+\mathrm{v}^{2} \mathrm{R}_{3}+\ldots+\mathrm{v}^{\mathrm{n}-1} \mathrm{R}_{\mathrm{n}}}{\sum_{\mathrm{n}=1} \mathrm{v}^{\mathrm{n}-1}}
$$

The optimal replacement policy of the equipment after $\mathrm{n}$ period is as follows:

i) Do not replace the equipment if the next period's cost is less than the weighted average of previous costs.

ii) Replace the equipments if the next period's cost is greater than the weighted average of previous costs.

If the salvage cost $S_{n}$ is not negligible, the expression (2) for weighted average cost is given by

$\mathrm{W}(\mathrm{n})=\frac{\mathrm{C}-\mathrm{S}_{\mathrm{n}} \mathrm{v}^{\mathrm{n}}+\sum_{\mathrm{n}=1} \mathrm{R}_{\mathrm{n}} \mathrm{v}^{\mathrm{n}-1}}{\sum_{\mathrm{n}=1} \mathrm{v}^{\mathrm{n}-1}}$

\section{THE PROPOSED MODEL}

Considering a realistic replacement problem, here, we assumed that the maintenance costs, salvage cost, and running costs with an imprecise value are expressed by fuzzy numbers. It increases with time and each fuzzy cost is to be paid just in the start of the period.

\subsection{Present Worth Factor}

Let the money carry a fuzzy rate of interest $\tilde{\mathrm{r}}$ per year when the value of money changes with time and $t$ is a discrete variable. If $\tilde{\mathrm{r}}$ be the rate of fuzzy interest, then $(1+\tilde{\mathrm{r}})^{-\mathrm{n}}$ is called the present worth factor or present value of one US\$ spent in $n$ year's time from now.

\subsection{Discount Rate}

The present worth factor of unit amount to be spent after one year is given by $\tilde{\mathrm{v}}=(1+\tilde{\mathrm{r}})^{-\mathrm{n}}$, when $\tilde{\mathrm{r}}$ is called the rate of fuzzy interest and $\tilde{\mathrm{v}}$ is called fuzzy discount rate. To find the optimal replacement policy, let initial cost of the equipment $\tilde{\mathrm{C}}$ and the operation cost in $n$ years $\tilde{R}_{n}$ be trapezoidal fuzzy numbers respectively. We also assume that $\tilde{\mathrm{r}}$ is a trapezoidal fuzzy number. We find the weighted average fuzzy cost of all the previous $\mathrm{n}$ years with weights $\tilde{1}, \tilde{\mathrm{v}}, \tilde{\mathrm{v}}^{2}, \ldots \tilde{\mathrm{v}}^{\mathrm{n}-1}$ respectively. 
Here, $\tilde{\mathrm{v}}$ is the depreciation value of money and it is always less than $\tilde{1}$ in ranking indexes. The expression for weighted average fuzzy cost is given by

$$
\tilde{\mathrm{W}}(\mathrm{n})=\frac{\tilde{\mathrm{C}}+\tilde{\mathrm{R}}_{1}+\tilde{\mathrm{v}} \tilde{\mathrm{R}}_{2}+\tilde{\mathrm{v}}^{2} \tilde{\mathrm{R}}_{3}+\ldots+\tilde{\mathrm{v}}^{\mathrm{n}-1} \tilde{\mathrm{R}}_{\mathrm{n}}}{1+\tilde{\mathrm{v}}+\tilde{\mathrm{v}}^{2}+\ldots+\tilde{\mathrm{v}}^{\mathrm{n}-1}}
$$

Hence, the optimal policy of the equipment after $\mathrm{n}$ period is as follows:

i. Do not replace the equipment if the next period's operating cost is less than weighted average of previous fuzzy costs.

ii. Replace the equipment if the next period's operating fuzzy cost is greater than the weighted average of pervious fuzzy costs.

\subsection{Algorithm for the Determination of Replacement Time and the Selection of Best Equipment}

To determine the fuzzy weighted average cost (or fuzzy annualized cost) we proceed as:

Step-1. Find the present value of fuzzy maintenance cost for each of the years that is, $\sum \tilde{R}_{n} \tilde{v}^{n-1}$ for $n=1,2$, $n$. where $\tilde{\mathrm{v}}=(1+\tilde{\mathrm{r}})^{-1}$.

Step-2. Calculate the sum of fuzzy initial cost and the accumulated present values obtained in Step-1 that is, $\tilde{\mathrm{C}}+\sum \tilde{\mathrm{R}}_{\mathrm{n}} \tilde{\mathrm{V}}^{\mathrm{n}-1}$.

Step-3. Subtract the fuzzy salvage value of equipment from the result obtained in Step-2. i.e. $\tilde{C}+\sum \tilde{R}_{n} \tilde{v}^{n-1}-\tilde{S}_{n}$

Step-4. Find the cumulative present value factor up to each of the years, that is $\sum \widetilde{v}^{n-1}$.

Step-5. Determine the annualized fuzzy cost $\tilde{\mathrm{W}}(\mathrm{n})$, by dividing the entries obtained in step- 3 by the corresponding entries obtained in step-4 i.e.

$$
\tilde{\mathrm{W}}(\mathrm{n})=\left(\tilde{\mathrm{C}}+\sum \tilde{\mathrm{R}}_{\mathrm{n}} \tilde{\mathrm{v}}^{\mathrm{n}-1}-\tilde{\mathrm{S}}_{\mathrm{n}}\right) / \sum \tilde{\mathrm{v}}^{\mathrm{n}-1}
$$

Step-6. Determine the Yager ranking index, defined in (1), and proposed by Yager, of corresponding annualized fuzzy cost to find out the minimum weighted average fuzzy cost in crisp environment. This minimum fuzzy cost indicates the replacement time of the equipments.

\section{EXAMPLES}

The fuzzy cost of a machine is US\$ $(5900,5950,6050,6100)$. The fuzzy running cost and the salvage value at the end of the year are given in Table 1.
Table 1. Fuzzy running cost and salvage cost

\begin{tabular}{|c|c|c|}
\hline $\begin{array}{c}\text { Year } \\
(\mathrm{n}) \\
\downarrow\end{array}$ & $\begin{array}{c}\text { Running cost } \\
\left(\tilde{\mathrm{R}}_{\mathrm{n}}\right)\end{array}$ & $\begin{array}{c}\text { Salvage Value } \\
\left(\tilde{\mathrm{S}}_{\mathrm{n}}\right)\end{array}$ \\
\hline 1 & $(1100,1150,1200,1270)$ & $(3800,3900,3950,4000)$ \\
\hline 2 & $(1300,1360,1400,1450)$ & $(2600,2650,2700,2760)$ \\
\hline 3 & $(1500,1580,1600,1650)$ & $(1900,1950,2000,2060)$ \\
\hline 4 & $(1800,1840,1850,1870)$ & $(1450,1470,1480,1500)$ \\
\hline 5 & $(2000,2030,2050,2070)$ & $(950,980,1000,1050)$ \\
\hline 6 & $(2350,2400,2460,2500)$ & $(550,570,590,600)$ \\
\hline 7 & $(2900,2920,2950,3000)$ & $(500,530,540,550)$ \\
\hline
\end{tabular}

Due to market fluctuations, let the fuzzy rate of interest be $(0.08,0.09,0.10,0.12)$ per year. Find when the machine is to be replaced.

Solution: To solve this problem, we first determine the present worth factor of the money to be spent in a year as $\tilde{\mathrm{v}}=(1+\tilde{\mathrm{r}})^{-1}$. Here 1 is a crisp number. Then we will still write it as a fuzzy number even though this fuzzy number is crisp. We can write crisp number 1 as a trapezoidal fuzzy number represented by $(1,1,1,1)$.

Then, $\tilde{v}=\{\tilde{1}+(0.08,0.09,0.10,0.12)\}^{-1}$

$=\{(1,1,1,1)+(0.08,0.09,0.10,0.12)\}^{-1}$

$=(1.08,1.09,1.10,1.12)^{-1}$ by $(2.5 .2)$

$\cong(1 / 1.12,1 / 1.10,1 / 1.09,1 / 1.08)$

$=(0.89,0.90,0.91,0.92)$.

Since the salvage value is considered, we use the expression (5).

For the value $\tilde{\mathrm{W}}(\mathrm{n})$, we

determine $\tilde{\mathrm{v}}^{\mathrm{n}-1}, \sum \tilde{\mathrm{v}}^{\mathrm{n}-1}, \sum \tilde{\mathrm{R}}_{\mathrm{n}} \tilde{\mathrm{v}}^{\mathrm{n}-1}, \tilde{\mathrm{C}}+\sum \tilde{\mathrm{R}}_{\mathrm{n}} \tilde{\mathrm{v}}^{\mathrm{n}-1}$, and

$\tilde{\mathrm{S}}_{\mathrm{n}} \widetilde{\mathrm{v}}^{\mathrm{n}}$ respectively (for $\mathrm{n}=1,2, \mathrm{n}$ ) with the help of definition

2.7.3 and 2.7.4. Then, the optimal replacement time is

determined (See Table 2).

Using definition 2.9 we obtain the Yager's ranking index

$\mathrm{Y}\left(\tilde{\mathrm{R}}_{5}\right)$, Y $\left(\tilde{\mathrm{R}}_{7}\right)$ and $\mathrm{Y}(\tilde{\mathrm{W}}(\mathrm{n}))$ (See Table 2$)$ as

$\mathrm{Y}\left(\tilde{\mathrm{R}}_{5}\right)=2297.50$, Y $\left(\tilde{\mathrm{R}}_{7}\right)=2942.50$.

Since, $2297.50<2853.59<2942.50$, we have

$\mathrm{Y}\left(\tilde{\mathrm{R}}_{5}\right)<\mathrm{Y}(\tilde{\mathrm{W}}(6))<\mathrm{Y}\left(\tilde{\mathrm{R}}_{7}\right)$.

So, the running cost of $5^{\text {th }}$ year is less than weighted average of $6^{\text {th }}$ year and running cost of $7^{\text {th }}$ year is greater than the weighted average of $6^{\text {th }}$ year. Therefore, the equipment is to be replaced at the end of $6^{\text {th }}$ year with a new one. 
Table 2. Determination of optimal replacement time

\begin{tabular}{|c|c|c|c|c|c|c|c|}
\hline & & & & & & & \\
\hline Year(n) & 1 & 2 & 3 & 4 & 5 & 6 & 7 \\
\hline$\tilde{\mathrm{R}}_{\mathrm{n}}$ & $\begin{array}{l}(1100,1150, \\
1200,1270)\end{array}$ & $\begin{array}{l}(1300,1360, \\
1400,1450)\end{array}$ & $\begin{array}{l}(1500,1580, \\
1600,1650)\end{array}$ & $\begin{array}{l}(1800,1840, \\
1850,1870)\end{array}$ & $\begin{array}{l}(2000,2030, \\
2050,2070)\end{array}$ & $\begin{array}{l}(2350,2400, \\
2460,2500)\end{array}$ & $\begin{array}{l}(2900,2920, \\
2950,3000)\end{array}$ \\
\hline$\tilde{\mathrm{v}}^{\mathrm{n}-1}$ & $\begin{array}{l}1.00, \\
1.00, \\
1.00, \\
1.00)\end{array}$ & $\begin{array}{l}0.89, \\
0.90, \\
0.91, \\
0.92)\end{array}$ & $\begin{array}{l}0.792, \\
0.810, \\
0.828, \\
0.846)\end{array}$ & $\begin{array}{l}(0.704, \\
0.729, \\
0.753, \\
0.778)\end{array}$ & $\begin{array}{l}0.627, \\
0.656, \\
0.685, \\
0.716)\end{array}$ & $\begin{array}{l}0.558, \\
0.590, \\
0.624, \\
0.659)\end{array}$ & $\begin{array}{l}0.496, \\
0.531, \\
0.567, \\
0.606)\end{array}$ \\
\hline$\tilde{\mathrm{R}}_{\mathrm{n}} \tilde{\mathrm{v}}^{\mathrm{n}-1}$ & $\begin{array}{l}(1100, \\
1150, \\
1200, \\
1270)\end{array}$ & $\begin{array}{l}(1157.00, \\
1224.00 \\
1274.00 \\
1334.00)\end{array}$ & $\begin{array}{l}\text { (1188.00, } \\
1279.80, \\
1324.80, \\
1395.90)\end{array}$ & $\begin{array}{l}1267.20, \\
1341.36, \\
1393.05, \\
1454.86)\end{array}$ & $\begin{array}{l}1254.00, \\
1331.68, \\
1404.25, \\
1482.12)\end{array}$ & $\begin{array}{l}(1311.30, \\
1416.00, \\
1535.04, \\
1647.05)\end{array}$ & $\begin{array}{l}1438.40, \\
1550.52, \\
1672.65, \\
1818.00)\end{array}$ \\
\hline$\sum \widetilde{\mathrm{R}}_{\mathrm{n}} \widetilde{\mathrm{V}}^{\mathrm{n}-1}$ & $\begin{array}{l}(1100, \\
1150, \\
1200, \\
1270)\end{array}$ & $\begin{array}{l}(2257.00, \\
2374.00, \\
2474.00, \\
2604.00)\end{array}$ & $\begin{array}{l}(3445.00, \\
3653.80, \\
3798.80, \\
3999.90)\end{array}$ & $\begin{array}{l}(4712.20, \\
4995.16, \\
5191.85, \\
5454.76)\end{array}$ & $\begin{array}{l}(5966.20, \\
6326.84, \\
6596.10 \\
6936.88)\end{array}$ & $\begin{array}{l}(7277.50, \\
7742.84, \\
8131.14, \\
8583.93)\end{array}$ & $\begin{array}{l}(8715.90, \\
9293.36, \\
9803.79, \\
10401.93)\end{array}$ \\
\hline$\tilde{\mathrm{S}}_{\mathrm{n}}$ & $\begin{array}{l}(3800,3900, \\
3950,4000)\end{array}$ & $\begin{array}{l}(2600,2650, \\
2700,2760)\end{array}$ & $\begin{array}{l}(1900,1950, \\
2000,2060)\end{array}$ & $\begin{array}{l}(1450,1470, \\
1480,1500)\end{array}$ & $\begin{array}{l}950,980, \\
1000,1050)\end{array}$ & $\begin{array}{l}(780,800, \\
850,900)\end{array}$ & $\begin{array}{l}(500,530, \\
540,550)\end{array}$ \\
\hline$\tilde{\mathrm{S}}_{\mathrm{n}} \tilde{\mathrm{v}}^{\mathrm{n}}$ & $\begin{array}{l}(3382.00, \\
3510.00, \\
3594.50, \\
3680.00)\end{array}$ & $\begin{array}{l}(2059.20, \\
2146.50, \\
2235.60, \\
2334.96)\end{array}$ & $\begin{array}{l}(1337.60, \\
1421.55, \\
1506.00, \\
1602.68)\end{array}$ & $\begin{array}{l}\text { (909.15, } \\
964.32, \\
1013.80, \\
1074.00)\end{array}$ & $\begin{array}{l}(530.10, \\
578.20, \\
624.00, \\
691.95)\end{array}$ & $\begin{array}{l}386.88, \\
424.80, \\
481.95, \\
545.40)\end{array}$ & $\begin{array}{l}(221.00, \\
253.34, \\
278.64, \\
306.35)\end{array}$ \\
\hline$\sum \tilde{\mathrm{v}}^{\mathrm{n}-1}$ & $\begin{array}{l}(1.00, \\
1.00, \\
1.00, \\
1.00)\end{array}$ & $\begin{array}{l}(1.89, \\
1.90, \\
1.91, \\
1.92)\end{array}$ & $\begin{array}{l}(2.682, \\
2.710, \\
2.738, \\
2.766)\end{array}$ & $\begin{array}{l}(3.386, \\
3.439, \\
3.491, \\
3.544)\end{array}$ & $\begin{array}{l}(4.013, \\
4.095, \\
4.176, \\
4.203)\end{array}$ & $\begin{array}{l}(4.571, \\
4.685, \\
4.800, \\
4.862)\end{array}$ & $\begin{array}{l}(5.067, \\
5.216, \\
5.367, \\
5.468)\end{array}$ \\
\hline $\begin{array}{l}\tilde{\mathrm{C}}-\tilde{\mathrm{S}}_{\mathrm{n}} \tilde{\mathrm{v}}^{\mathrm{n}} \\
+\sum \tilde{\mathrm{R}}_{\mathrm{n}} \tilde{\mathrm{v}}^{\mathrm{n}-1}\end{array}$ & $\begin{array}{l}\text { (3320.00, } \\
3505.50, \\
3740.00, \\
3988.00)\end{array}$ & $\begin{array}{l}\text { (5822.04, } \\
6088.40, \\
6377.50, \\
6644.80)\end{array}$ & $\begin{array}{l}\text { (7742.32, } \\
8097.80, \\
8427.25, \\
8762.30)\end{array}$ & $\begin{array}{l}(9538.20, \\
9931.36, \\
10277.53, \\
10645.61)\end{array}$ & $\begin{array}{l}(11174.25, \\
11652.84, \\
12067.90, \\
12506.78)\end{array}$ & $\begin{array}{l}\text { (12632.10, } \\
13210.89, \\
13756.34, \\
14297.05)\end{array}$ & $\begin{array}{l}(14309.55, \\
14964.72, \\
15600.45, \\
16280.93)\end{array}$ \\
\hline$\tilde{\mathrm{W}}(\mathrm{n})$ & $\begin{array}{l}(3382.00, \\
3505.50, \\
3740.00, \\
3988.00)\end{array}$ & $\begin{array}{l}\text { (3032.31, } \\
3187.64, \\
3356.57, \\
3515.76)\end{array}$ & $\begin{array}{l}(2799.10, \\
2957.56, \\
3109.68, \\
3267.07)\end{array}$ & $\begin{array}{l}2691.36, \\
2844.84, \\
2988.52, \\
3144.00)\end{array}$ & $\begin{array}{l}(2658.63, \\
2790.43, \\
2946.98, \\
3116.56)\end{array}$ & $\begin{array}{l}\text { (2598.10, } \\
2752.26, \\
2936.25, \\
3127.77)\end{array}$ & $\begin{array}{l}\text { (2608.37, } \\
2788.28, \\
2990.88, \\
3213.13)\end{array}$ \\
\hline $\mathrm{Y}(\tilde{\mathrm{W}}(\mathrm{n}))$ & 3653.87 & 3273.07 & 3033.35 & 2917.18 & 2878.15 & $\begin{array}{l}2853.59 \\
\text { (Replace) }\end{array}$ & 2900.16 \\
\hline
\end{tabular}

\section{CONCLUSIONS}

Modeling of replacement problem it is often observed that the parameters of the problem are not known precisely. This impreciseness is handled by using fuzzy numbers, as it is expected to express the situation more realistically. In this paper, to deal with this uncertainty, we present fuzzy replacement problem when the capital cost, scrap value, maintenance or running cost are trapezoidal or triangular fuzzy numbers. To get closer to our daily life situation, we have considered also, the rate of interest as an imprecise value due to non-stability of the value of money. We thus determine the present worth factor of money to get fuzzy weighted average cost. We use Yager's ranking method to compare of fuzzy weighted average costs for finding out the optimal replacement time. The proposed procedure is simple, effective and realistic.
A numerical example, where all the parameters are taken as positive trapezoidal fuzzy numbers, is provided to demonstrate the effectiveness of the proposed approach. We hope the proposed approach presented here may be useful for future study for replacement of equipments that break down suddenly. We further hope that our proposed approach will contribute for studying replacement problem involving technological improvement of equipment.

\section{ACKNOWLEDGMENTS}

The authors are very grateful to the anonymous referees for their comments and suggestions, which have led to improve the quality and presentation of the paper to its current standard. 


\section{REFERENCES}

[1] Bellman, R.E., 1955. Equipment replacement policy. SIAM Journal Applied Mathematics 3,133-136.

[2] Alchian, A.A.1952. Economic Replacement Policy. Technical Report Publication R-224. The RAND Corporation, Santa Monica, CA.

[3] Dreyfus, S.E., and Law, A.M. 1977. The Art and Theory of Dynamic Programming. Academic Press, New York.

[4] Ohnishi, M.1997. Optimal minimal- repair and replacement problem under average cost criterion: optimality of $(t, T)$ policy. Journal of the Operations Research Society of Japan 40(3), Sept.

[5] Dimitrakos, T.D., and Kyriakidis, E.G. 2007. An improved algorithm for the computation of the optimal repair/replacement policy under general repairs. European Journal of Operational Research 182, 775-782

[6] Mahdavi, M., and Mahdavi, M. 2009. Optimization of age replacement policy using reliability based heuristic model. Journal of Scientific \& Industrial Research 68, 668-673.

[7] Zhao, X. F., Chen, M., Nakagawa, T. 2010. Three kinds of replacement models combined with additive and independent damages. In Proceedings of the Ninth International Symposium on Operations Research and Its Applications (ISORA'10), 31-38.

[8] Nezhad, M. S. F., Niaki, S. T. A., Jahromi, A. E. 2007. A One-stage two-machine replacement strategy based on the Bayesian inference method. Journal of Industrial and Systems Engineering 1(3), 235-250.

[9] Von Neumann, J., and Morgenstern, O. 1944. Theory of Games and Economic Behavior. Princeton University Press, Princeton, NJ.

[10] Zadeh, L.A. 1965. Fuzzy sets, Information and Control 8, 338-352.

[11] Buckley, J. 1987. The fuzzy mathematics of finance. Fuzzy Sets and Systems 21, 257-273.

[12] Buckley, J. 1992. Solving fuzzy equations in economics and finance. Fuzzy Sets and Systems 48, 289-296.

[13] Choobineh, F., and Behrens, A. 1992. Use of intervals and possibility distributions in economic analysis. Journal of the Operational Research Society 43(9), 907-918.
[14] Ward, T. 1985. Discounted fuzzy cash flow analysis. In Proceedings of the 1985 Fall Industrial Engineering Conference, 476-481.

[15] Chiu, C., and Park, C. 1994. Fuzzy cash flow analysis using present worth criterion. The Engineering Economist 39(2), 113-138.

[16] Biswas, P., and Pramanik, S. 2011. Application of fuzzy ranking method to determine the replacement time for fuzzy replacement problem. International Journal of Computer Applications (July 2011), 25(11), 41-47.

[17] Yager, R.R. 1981. A procedure for ordering fuzzy subsets of the unit interval. Information Sciences 24, 143-161

[18] Dubois, D., and Prade, H. 1980. Fuzzy Sets and Systems: Theory and Applications. Academic Press, New York.

[19] Dubois, D., and Prade, H. 1978. Operations on fuzzy numbers. International Journal of Systems Science 9, 612626.

[20] Dubois, D., and Prade, H. 1987. Fuzzy numbers: an overview. In Bezdek, J., editor, Analysis of Fuzzy Information, 1, 3-39. CRC Press, Boca Raton, FL.

[21] Kauffmann, A., and Gupta, M. 1991. Introduction to fuzzy Arithmetic: Theory and Applications. Van Nostrand Reinhold, New York.

[22] Bansal, A. 2011. Trapezoidal fuzzy number (a, b, c, d): arithmetic behavior. International Journal of Physical and Mathematical Sciences, 39-44.

[23] Klir, G. and Yuan, B. 1995. Fuzzy Sets and Fuzzy Logic: Theory and Applications. Prentice Hall PTR, Upper River Saddle, NJ.

[24] Zadeh, L. A. 1978. Fuzzy sets as a basis for a theory of possibility. IEEE Transactions on Systems, Man, and Cybernetics 1, 3-28.

[25] Zimmerman, H. 1991. Fuzzy Set Theory and Its Applications. Kluwer Academic Press, Boston, MA, second edition.

[26] Karsak, E. E., and Tolga, E. 2001. Fuzzy multi-criteria decision-making procedure for evaluating advanced manufacturing system investments. Int. J. Production Economics 69, 49-64. 